\title{
Changes in endogenous cytokinins during flowering induction in Douglas fir: effect of exogenous applications
}

\author{
N. Imbault ${ }^{1}$, P. Doumas ${ }^{2}$, C. Joseph ${ }^{1}$ and M. Bonnet-Masimbert ${ }^{2}$ \\ 1 Laboratoire des Composés Phénoliques, Université d'Orléans, 45067 Orléans Cedex, and \\ 2 INRA, Station d'Amélioration des Arbres Forestiers, Ardon, 45160 Olivet, France
}

\section{Introduction}

The involvement of plant growth substances (PGS) in flowering promotion in conifers was analyzed in relation to the level of gibberellins (Pharis et al., 1987). However, in herbaceous species, cyiokinins are sometimes considered as one of the componeris which promote flowering (Bernier et al., 1977; Lejeune et al., 1988). In Douglas fir, some treatments, such as fertilization, stem girdling, root pruning or root flooding, can favor flowering (BonnetMasimbert, 1982). Roots are also considered to be the major site of cytokinin synthesis (Kende, 1964). Endogenous cytokinins were analyzed in Douglas fir, initially in the sexual buds and then in the shoots during floral differentiation. Then, the observed changes in the compound assimilated to isopentenyladenine (iP) led to the study of an effect of this compound on flowering.

\section{Materials and Methods}

it: $\cdot$ ud buds of Douglas fir (Pseudotsuga men(a) wete collected from the same $10 \mathrm{yr}$ old tree in April during the time of "bud development'.

Shoots were collected from 5 yr old ramets of the same clone. They were subjected to different treatments at the time of bud burst: 1) control; 2) stem perfusion of an aqueous solution of gibberellins $A_{4 / 7}$ plus naphthyl acetic acid; 3 ) alternate root flooding ( $21 / 2 \mathrm{~d}$ in water and $21 / 2 \mathrm{~d}$ out) for $3 \mathrm{wk} ; 4)$ combination of treatments 2 and 3 . Shoots were collected 3 and 6 wk after bud burst.

Exogenous iP was applied to shoots of $6 \mathrm{yr}$ old trees.

Cytokinin bases and ribosides were extracted and analyzed as described by Imbault et al. (1988). Cytokinin nucleotides were extracted with $10 \%$ perchloric acid, purified on a cellulose phosphate column and on a carboxylic acid column before separation by high performance liquid chromatography (HPLC) using an anion exchange column Partisil 10 SAX (Whatman) to separate the mono-, di- and triphosphate cytokinins, and a C18 column (Beckman Ultraspher, $5 \mu \mathrm{m}$ ) to separate the compounds of the zeatin family from those from the iP family in the monophosphate zone (Laloue, personal communication). Cylokinins cochromatographing with standards and which were recognized by antibodies directed against isopentenyladenosine (iPA) or ribosylzeatin ( $R Z$ ) were quantified by radioimmunoassay.

In another experiment, if was exogenously applied. The modalities consisted of the application of 3 quantities of iP $(0,0.5,5 \mu \mathrm{g}): 2$ types of solvent (ethanol or water with $0.05 \%$ Aromox 


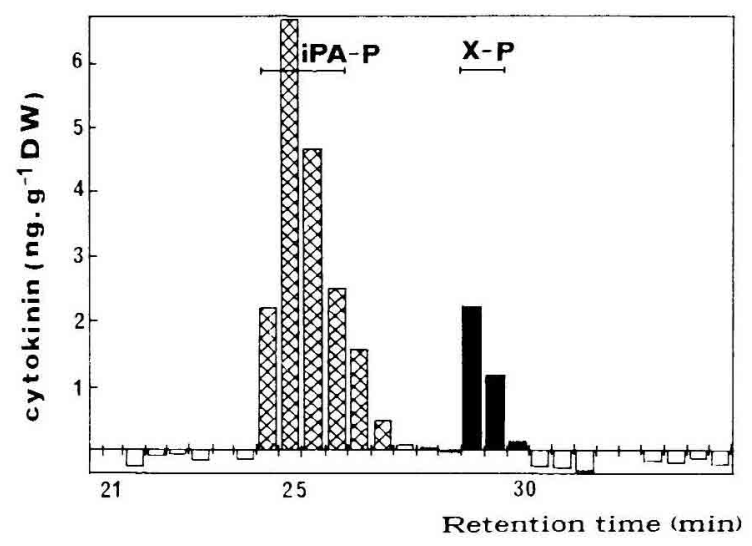

Fig. 1. Immunohistogram of male bud fractions collected after HPLC. RIA run with anti-iPA antibodies. iPA-P: isopentenyladenosine monophosphate; $X-P$ : unknown cytokinin.

C); 2 zones of application (distal 1/3 or proximal $2 / 3$ of the shoot); 2 dates of application ( 3 or 6 wk after individual bud burst). The following spring, male and female strobili were counted on each shoot.

a

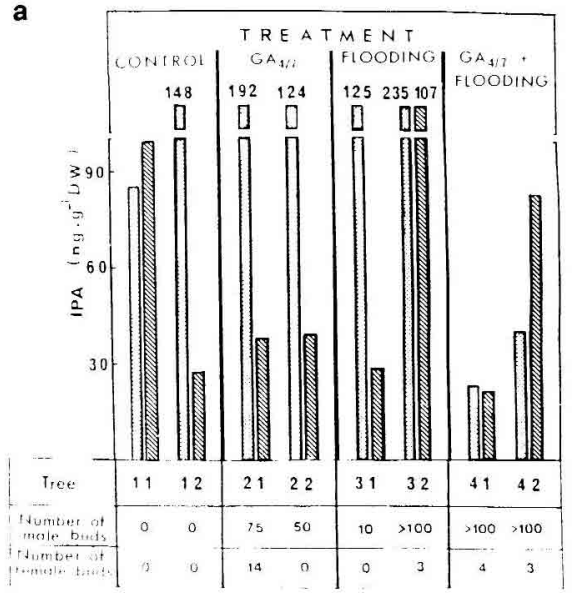

\section{Results}

Cytokinin bases and ribosides were analyzed in the sexual buds. Male and female

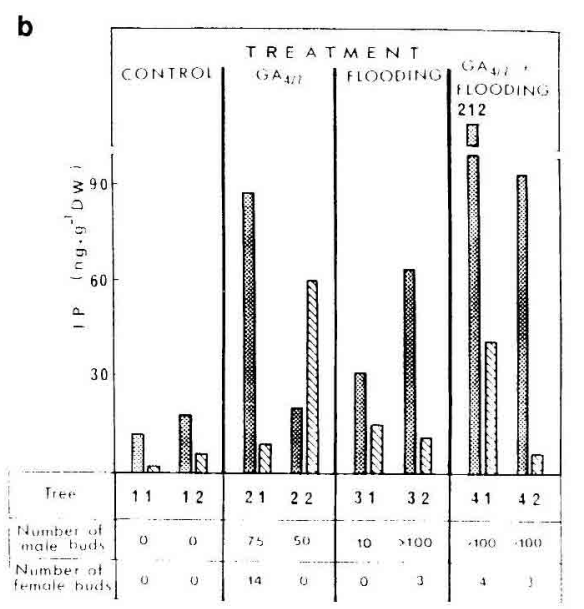

Fig. 2. Amount of isopentenyladenosine (iPA) and isopentenyladenine (iP) in shoots from 8 analyzed trees. Effect of treatments at 2 collection times: 3 wk after bud burst; $\$$ : 6 wh after bud burst. 
buds presented the same peaks, corresponding to the $\mathrm{IP}$, iPA, zeatin and $R Z$ retention times. There was a supplementary peak before the $R Z$ one in the female buds; this peak has not yet been identified. We did not observe any differences in forms of the monophosphate nucleotides. They had the same retention time peaks as $R Z$ monophosphate, dihydrozeatin monophosphate and IPA monophosphate standards (Fig. 1). This unidentified peak had neither the same retention time as the IPA monophosphate standard nor that of the iP or the IPA standard but it reacted with the anti-iPA antibodies. It could correspond to another form of cytokinin nucleotides.

Bases and ribosides were also analyzed in Douglas fir shoots during floral differentiation after induction by different treatments. Only the iP-iPA zone is presented. Fig. 2a shows the results of compounds cochromatographing with iPA. The quantities of IPA were not related to the flowering or to the treatment. Compounds cochromatographing with iP are represented in Fig. 2b. Like iPA, no relation could be established between the treatments and the iP rate; but there seemed to be a relationship between the iP rate and female flowering.

In our other experiment, exogenous iP was applied to shoots to confirm its possible effect on flowering. iP had no significant effect on male flowering (Fig. 3a) but it had a positive effect on female flowering (Fig. 3b) at the highest dosage (5 $\mu \mathrm{g}$ per shoot) and in the early treatments ( $3 \mathrm{wk}$ after bud burst), given at a time when floral differentiation could occur (Owens, 1969).

Fig. 3. Effects of the different modalities of iP application on the number of male (a) and female (b) buds. Date of application: $3(3 w)$ or 6 wk $(6 w)$ after bud burst. Dilution of iP: alcohol (Alc) or water with Aromox C (Arom). Zone of application on the shoots: distal (dist) or proximal (prox). Amounts of applied iP: 0,500 or $5000 \mathrm{ng}$. For each analyzed factor, only the values topped by the letter ' $b$ ' are significantly different ( $5 \%$ level, Juncan's multiple range test).

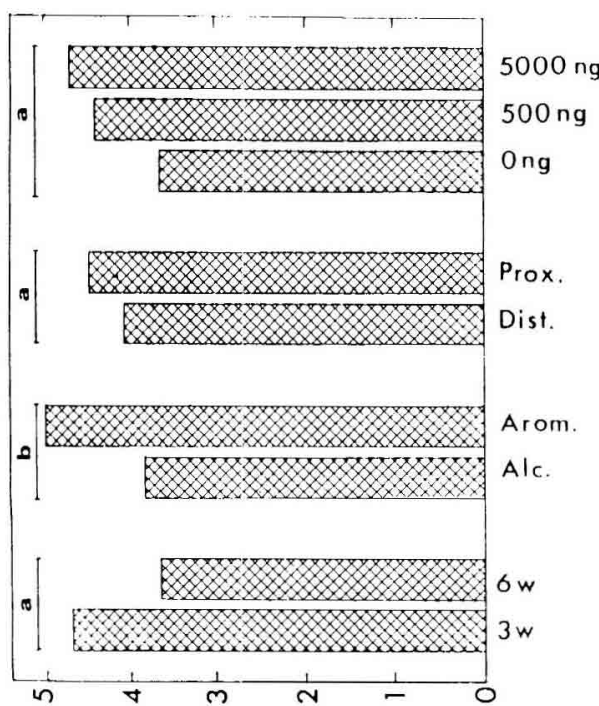

a

number of male buds

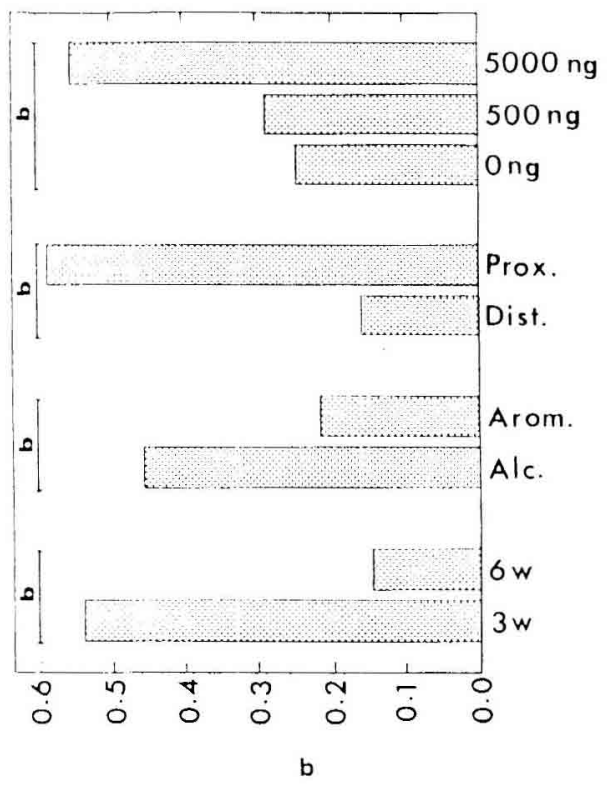

number of female buds 


\section{Conclusion}

Besides gibberellins and probably some other PGS, iP may be one of the components involved in hormonal regulation of flower promotion in Douglas fir. However, it is certainly not the only one and these results will be compared later to those obtained with other PGS in the same shoots.

\section{References}

Bernier G., Kinet J.M., Jacmard A., Havelange I. \& Bodson M. (1977) Cytokinin as a possible component of a floral stimulus in Sinapis alba. Plant Physiol. 60, 282-285

Bonnet-Masimbert M. (1982) Influence de l'état d'activité des racines sur la floraison induite par les gibberellines 4 et 7 chez Pseudotsuga menziesii (Mirb.) Franco. Silvae Genet. 21, 178188

Imbault N., Tardieu I., Joseph C., Zaerr J.B. \& Bonnet-Masimbert M. (1988) Possible role of isopentenyladenine and isopentenyladenosine in flowering of Pseudotsuga menziesii: endogenous variations and exogenous applications. Plant Physiol. Biochem. 26, 289-295

Kende H. (1964) Preservation of chlorophyll in leaf sections by substances obtained from root exudates. Science 163, 1066-1067

Lejeune P., Bernier G. \& Kinet J.M. (1988) Cytokinin fluxes during floral induction in the long day plant Sinapis alba L. Plant Physiol. 86, 1095-1098

Owens J.N. (1969) The relative importance of initiation and early development on cone production in Douglas fir. Can. J. Bot. 47, 10301049

Pharis R.P., Webber J.E. \& Ross S.D. (1987) The promotion of flowering in forest trees by gibberellin A4/7 and cultural treatments: a review of the possible mechanisms. For. Ecol. Manage. 19, 65-84 